\title{
JOVENS COMO FOCO DAS POLÍTICAS DE EDUCAÇÃO PROFISSIONAL: O PROGRAMA NACIONAL DE INTEGRAÇÃO DA EDUCAÇÃO PROFISSIONAL COM A EDUCAÇÃO BÁSICA NA MODALIDADE DE EDUÇÇÇÃO DE JOVENS E ADULTOS - PROEJA
}

\author{
GUIMARAES, Gabriela Rocha ${ }^{1}$ \\ GRACIOLI, Maria Madalena ${ }^{2}$
}

RESUMO: A partir dos anos 2000, a temática juventude adentra com maior ênfase na sociedade brasileira. Entretanto, a análise das políticas públicas destinadas aos jovens no período entre 1995 e 2002, no âmbito federal, evidencia que não havia consenso acerca de quem eram esses sujeitos. Com a posse de Luiz Inácio Lula da Silva, as políticas para juventude ganham destaque e entre elas, as educação profissional que coloca os jovens como principal público-alvo. Tendo como foco essas políticas, este estudo, de cunho bibliográfico, intenciona apresentar de maneira sucinta o Programa Nacional de Integração da Educação Profissional com a Educação Básica na Modalidade de Educação de Jovens e Adultos - PROEJA, que tem em seu núcleo jovens e adultos, e refletir sobre as representações que "trabalho" e "educação" assumem no modo de produção capitalista, bem como, sobre o impacto de tais representações na vida dos jovens. As reflexões aqui apresentadas apontam para um "apagamento" do PROEJA com o surgimento do Pronatec, consequência do direcionamento de investimentos, que se tornou maior com a implantação desse novo Programa. Espera-se suscitar debates e reflexões acerca da temática, retomando questões sobre educação e capital e sua relação com a empregabilidade sem, contudo, trazer certezas e finalizações.

Palavras-Chave: Juventude. Educação profissional. PROEJA.

\section{INTRODUÇÃO}

O reconhecimento da juventude como categoria social e não apenas uma faixa etária limitada por idades, mas considerada em sua diversidade, é ainda muito recente. No Brasil, somente nas duas últimas décadas, a temática da juventude passa a fazer parte das agendas das políticas públicas e, com a posse de Luís Inácio Lula da Silva na presidência do país, houve um aceno positivo para o reconhecimento dos jovens como destinatários de políticas públicas; desse modo, a partir de 2004, inicia-se um amplo diálogo entre governo e movimentos sociais sobre a necessidade de criar uma política nacional de juventude. Muitos desafios eram apontados, entre eles, estava, por um lado, a criação de políticas que possibilitassem sanar as diversas situações de vulnerabilidade e risco social em que grande parte dos jovens brasileiros estavam submetidos, e, por outro, políticas que pudessem oferecer oportunidades de múltiplas inserções sociais no sentido de integrar as várias esferas sociais. Assim, desde o ano de 2005, muitos esforços foram feitos gerando mecanismos que levaram à criação de uma Política Nacional de Juventude e da elaboração do Estatuto da Juventude.

Frente a essas afirmações, é crucial, portanto, conceituar políticas públicas. É certo que existem várias definições para políticas públicas, que podem ser entendidas "como conjunto de decisões e ações destinadas à resolução de problemas políticos” (RUA, 1998, p. 731). Assim, depreende-se que alguns

\footnotetext{
${ }^{1}$ Mestranda do Programa de Pós-graduacao em Planejamento e Analise de Políticas Públicas - UNESP, Franca.Graduada em Letras, especialista em Supervisão e Inspeção Escolar. Atualmente é Técnica em Assuntos Educacionais no IFSULDEMINAS, Campus Passos. E-mail: gabi.metzker@ hotmail.com

${ }^{2}$ Professora do Programa de Pós-Graduação em Análise e Planejamento de Políticas Públicas - UNESP, Franca, professora e coordenadora de curso da Faculdade de Filosofia Ciências e Letras de Ituverava, doutora em Sociologia com pós-doutorado pelo Centro de Estudos Sociais da Universidade de Coimbra. E-mail: lenagracioli@gmail.com
} 
processos serão foco de tais políticas no momento em que alcançarem o status de problemas políticos, passando a ocupar a agenda pública.

Ressalta-se que muitos debates sobre juventude comumente restringem-se a temas relacionados à

violência, tráfico e uso de drogas, gravidez precoce, entre outros que colocam os jovens como problemas, por isso tão importante se faz as políticas de juventude, em que reconheça a vulnerabilidade social a que muitos jovens estão submetidos, bem como a criação de muitos programas e projetos capazes de atender as especificidades e diversidade dos jovens de diferentes regiões do país.

Dentre os diversos programas criados com a Política Nacional de Juventude, apresentamos o Programa Nacional de Integração da Educação Profissional com a Educação Básica na Modalidade de Educação de Jovens e Adultos - PROEJA, que tem como público-alvo jovens e adultos - em sua maioria trabalhadores - que por motivos diversos não tiveram a oportunidade e/ou não puderam estudar na idade regular.

A opção por trabalhar com o PROEJA se justifica principalmente pelas características do público atendido pelo programa. São jovens e adultos que, no passado, já foram privados de direitos e que são vislumbrados enquanto mão de obra, mas esquecidos, por vezes, enquanto sujeitos de direitos. Nesse sentido, tornam-se relevantes estudos que busquem evidenciar como, efetivamente, essa expressiva parcela da população vem sendo atendida. Outro motivo que também contribui para essa escolha é o fato de que, o PROEJA perdeu espaço a partir da criação do Programa Nacional de Acesso ao Ensino Técnico e Emprego - PRONATEC (HORA, 2014). Como os investimentos no PRONATEC eram maiores, o PROEJA tornou-se "menos sedutor" aos olhos das instituições e acabou caindo no esquecimento. É justamente por se encontrar nessa condição, e por tantos jovens e adultos que ainda almejam o acesso ao ensino, que se torna necessário resgatá-lo no seu importante papel enquanto política de educação e formação profissional. Consideramos que, se bem implementado, o programa pode possibilitar a elevação da escolaridade e a inserção profissional de muitos jovens e adultos. Dessa forma, este texto que tem como objetivo discutir a importância do PROEJA, enquanto política pública relevante de educação e formação profissional, que segue na contramão daqueles que, comumente, optam por trabalhar com programas que recebem maior aporte de recursos econômicos.

Contudo, antes de adentrar na questão da educação profissional, torna-se imperativo problematizar as diversas e complexas relações estabelecidas entre juventude, trabalho e educação no sistema capitalista.

$\mathrm{O}$ trabalho pedagógico pode se constituir em uma das formas de manifestação do capital. Por intermédio do trabalho pedagógico, busca-se disciplinar a população a partir da construção de uma visão de mundo que atenda às demandas do capital. As representações acerca de trabalho e educação são construídas e reconstruídas segundo os processos produtivos e sociais vigentes. Se no taylorismo/fordismo essa relação era pautada pela força física, no toyotismo exige-se do trabalhador a aquisição de habilidades e competências superiores, bem como a elevação de seu nível de escolaridade (KUENZER, 2005).

Destaca-se, ainda, a tese da empregabilidade, que tomou os discursos a partir dos anos de 1990, buscando responsabilizar os indivíduos por sua exclusão do mercado de trabalho e mascarando o desemprego estrutural que assola o sistema capitalista (GENTILI, 2005).

Nesse contexto, sobretudo os jovens, têm suas vidas diretamente afetadas por esses discursos, que buscam responsabilizá-los por seu fracasso e instigá-los à competição. Trabalho e educação deixam de ser concebidos enquanto direitos do cidadão e ganham conotação de investimento. É preciso descortinar as bases que fundamentam esses discursos e buscar, nos espaços de contradição, a efetivação de uma formação emancipadora. 


\section{JUVENTUDE, TRABALHO E EDUCAÇÃO}

O Estatuto da Juventude, instituído pela Lei $\mathrm{N}^{\circ} 12.852$ de 05 de agosto de 2013, considera jovens as

pessoas com idade entre 15 e 29 anos.

No Brasil, a percepção dos jovens enquanto sujeitos de direitos é recente. Durante muito tempo na história brasileira, inexistiram políticas direcionadas especialmente a essa parcela da população. Contudo, a partir do final dos anos de 1990, inicia-se um processo de mudança nesse cenário. A temática juventude ganha espaço na sociedade e torna-se evidente, por meio da análise de projetos e programas direcionados aos jovens no período que vai de 1995 até 2002, na esfera federal, a inexistência de um consenso acerca de quem seja esse indivíduo (SPOSITO; CARRANO, 2003).

Ao considerar as políticas públicas destinadas à juventude, torna-se relevante partir do pressuposto da diversidade pela qual esses sujeitos são afetados. Sposito; Carrano (2003, p.17) afirmam que "tem sido recorrente a importância de se tomar a ideia de juventude em seu plural - juventudes -, em virtude da diversidade de situações existenciais que afetam os sujeitos". Tal afirmação corrobora que, no Brasil, há diferença entre ser jovem branco ou negro, entre viver na zona urbana ou rural, entre ser homem ou mulher, e que toda essa pluralidade deve ser reconhecida no processo de elaboração das políticas públicas destinadas aos jovens.

De acordo com a "teoria do capital humano", desenvolvida por Theodore Schultz, nas décadas de 1950 e 1960, o desenvolvimento individual e social dependeria do investimento de cada pessoa em educação. Essa teoria apoia-se no pressuposto de que os indivíduos possuem livre-arbítrio e, por isso, são responsáveis por seu destino. Dessa forma, as diferenças na distribuição de renda e as desigualdades sociais são determinadas por suas escolhas: alguns decidem investir em educação, o que lhes garantirá maior renda e melhores condições de vida, enquanto outros se conformam com sua situação subalterna (GALVÃO, 2007).

Sobre essa visão de educação advinda da "teoria do capital humano" Saviani $(2005$, p.22) aponta que:

Os dispêndios com educação passaram a ser considerados desejáveis, não apenas por razões sociais ou culturais, mas especificamente por motivos econômicos, e transformam-se num investimento de retorno ainda mais compensador do que outros tipos de investimento ligados à produção material. A educação passou, pois, a ser concebida como dotada de um valor econômico próprio e considerada um bem de produção (capital) e não apenas de consumo (grifo nosso).

Entre os anos de 1950 e 1970, acrescenta Saviani (2005), buscou-se alinhar a educação às necessidades do taylorismo/fordismo por meio da "pedagogia tecnicista". Já a partir do final dos anos de 1980 as escolas e o trabalho pedagógico buscaram uma nova forma de disciplinamento, desta vez, servindo aos interesses das reformas neoliberais e do toyotismo.

Pode-se dizer que o capitalismo encontra no trabalho pedagógico uma forma de manifestação. Assim, a finalidade do trabalho pedagógico é o disciplinamento que colabora com a construção de uma concepção de mundo, que, por sua vez, estará subordinada ao desenvolvimento das forças produtivas.

A pedagogia operante no fordismo tinha por objetivo educar trabalhadores e dirigentes fundamentando-se no rompimento entre pensar e agir. O modelo de produção era organizado em unidades fabris contando com grandes contingentes de trabalhadores submetidos a uma estrutura rigidamente hierarquizada.

A partir dos anos de 1990, os ideais neoliberais, a globalização e as consequentes mudanças no mundo do trabalho passaram a exigir novas formas de disciplinamento. Ciência e Tecnologia 
incorporaram-se aos processos produtivos e sociais exigindo do trabalhador a ampliação de sua escolaridade, bem como o desenvolvimento de novas habilidades e competências. Para atender às novas demandas do processo de acumulação flexível, a partir da formação de um novo tipo de trabalhador, era

necessária uma nova pedagogia, que se tornou conhecida como pedagogia das competências (KUENZER, 2005).

Dessa maneira, depreende-se que as relações entre trabalho e educação se compõem e se (re)compõem a partir dos processos produtivos e sociais vigentes:

A relação entre educação e trabalho, mediada no taylorismo/fordismo por modos de fazer - o que vale dizer, mediada pela força física, pelas mãos ou por habilidades específicas que demandavam coordenação fina ou acuidade visual, para dar apenas alguns exemplos -, passa a ser mediada pelo conhecimento, compreendido enquanto domínio de conteúdos e de habilidades cognitivas superiores (KUENZER, 2005, p.86).

Ademais, não se pode deixar de mencionar o discurso da empregabilidade, que ganhou força a partir dos anos de 1990. Tal conceito é definido como eixo articulador de um conjunto de políticas supostamente destinadas a reduzir os riscos sociais do desemprego. Porém, tal conceituação e seu uso em discursos correntes representam um engodo, na medida em que o desemprego no mercado de trabalho capitalista configura-se como problema estrutural.

Pode-se dizer que a tese da empregabilidade resgata a concepção do desenvolvimento individual proposta na "teoria do capital humano", mas abandona a correlação entre desenvolvimento do capital humano individual e capital humano social. Assim, o ingresso do indivíduo no mercado de trabalho depende de um conjunto de saberes e competências que o torna apto a competir pelos empregos disponíveis. E hoje, afirma Gentili (2005), as economias podem crescer e se desenvolver convivendo com grandes taxas de desemprego e com uma grande parcela de excluídos; ou seja, o desenvolvimento da economia não depende da inclusão de todos aos processos produtivos.

Busca-se, mais uma vez, conformar e responsabilizar os indivíduos pelo seu fracasso. Sobre a empregabilidade, Gentili (2005, p. 54) acrescenta que:

Um incremento no capital humano individual aumenta as condições de empregabilidade do indivíduo, o que não significa, necessariamente, que, por aumentar suas condições de empregabilidade, todo indivíduo terá seu lugar garantido no mercado... Simplesmente, porque no mercado não há lugar para todos. "Empregabilidade" não significa, então, para o discurso dominante, garantia de integração, senão melhores condições de competição para sobreviver na luta pelos poucos empregos disponíveis: alguns sobreviverão, outros não.

Kuenzer (2005) também apresenta a relação entre o mundo do trabalho e a educação, no toyotismo, utilizando-se das expressões "exclusão includente" e "inclusão excludente". A autora aponta a realização de estudos que permitem identificar, com relação ao mercado, estratégias que, em um primeiro momento, excluem os trabalhadores do mercado formal, no qual possuem melhores condições de trabalho e renda para, em seguida, incluí-los em condições precárias: por meio da terceirização, do trabalho informal e/ou com menores salários, fato que dinamiza e impulsiona as cadeias produtivas no regime de acumulação flexível. A essa ideia associa-se a expressão "exclusão includente".

Com relação à educação, identificam-se estratégias de inclusão escolar, mas sem considerar o fator qualidade, o que inviabiliza a formação de cidadãos autônomos e críticos que possam se opor às demandas do capital. Nessa esfera a expressão relacionada é "inclusão excludente". 
É importante lembrar que a Constituição Federal de 1988 concebe, em seu Art. 6º a educação e o trabalho enquanto direitos sociais e, reforçando essa ideia, o Estatuto da Juventude (2013) apresenta respectivamente, em seu Art. $7^{\circ}$ e Art. $14^{\circ}$, a educação de qualidade e a profissionalização, o trabalho e a renda como direitos dos jovens.

A partir dessas reflexões, percebe-se que as representações de trabalho e educação no modo de produção capitalista acabam por esvaziar a concepção de direito, indo de encontro ao preconizado nos dispositivos legais supracitados. Nesse contexto, trabalho e educação ganham conotação de investimento. $\mathrm{E}$ os jovens, que se constituem em grande contingente de força trabalhadora, têm suas vidas diretamente afetadas por esses discursos, na medida em que são instigados à competição e diretamente responsabilizados por seu insucesso.

Conforme Abad (2008) a partir dos anos 1990, principalmente nos países da América Latina, as políticas destinadas a juventude se voltaram para a inserção dos 'excluídos' no setor produtivo. Considerando o caso brasileiro especificamente a partir dos anos de 2002, a formação profissional ganha destaque, mediante um cenário de desenvolvimento econômico e aumento nas taxas de emprego com consequente necessidade de mão de obra. Assim, os jovens tornam-se o principal alvo das políticas públicas de educação profissional.

Nesse sentido, torna-se importante refletir acerca das representações de trabalho e educação que emergem no modo de produção capitalista, bem como de que forma tais representações afetam a vida dos jovens. Por conseguinte, não seria possível adentrar na questão da educação profissional, sem antes apontar essa contextualização. Após essa discussão, apresentaremos o Programa Nacional de Integração da Educação Profissional com a Educação Básica na Modalidade de Educação de Jovens e Adultos PROEJA.

\section{PROGRAMA NACIONAL DE INTEGRAÇÃO DA EDUCAÇÃO PROFISSIONAL COM A EDUCAÇÃO BÁSICA NA MODALIDADE DE EDUCAÇÃO DE JOVENS E ADULTOS - PROEJA}

A Lei de Diretrizes e Bases da Educação Nacional - LDB, no parágrafo $3^{\circ}$ do Art. 37, dispõe que "A educação de jovens e adultos deverá articular-se, preferencialmente, com a educação profissional, na forma do regulamento". Indo ao encontro do proposto pela LDB, foi criado o Programa Nacional de Integração da Educação Profissional com a Educação Básica na Modalidade de Educação de Jovens e Adultos - PROEJA FIC.

O PROEJA foi instituído pelo Governo Federal, no ano de 2005, por meio do Decreto $\mathrm{n}^{\circ} 5.478$, de 24 de junho. Contudo, em 2006 foi publicado o Decreto $n^{\circ}$ 5.840, de 13 de julho, em substituição ao anterior, que se tornou sua principal base legal.

O Programa tem como público-alvo, de acordo com o Ministério da Educação - MEC, "Jovens e adultos que não tiveram a oportunidade de cursar o ensino fundamental e/ou o ensino médio na idade regular e que busquem também uma profissionalização”. O programa abrange duas modalidades de oferta: a formação inicial e continuada de trabalhadores e a educação profissional técnica de nível médio.

O PROEJA FIC possui carga horária total mínima de 1400 horas, das quais 1200 horas, no mínimo, são destinadas à formação geral e 200 horas, no mínimo, à formação profissional. É destinado a estudantes da EJA que estejam cursando o Ensino Fundamental ou Médio.

O PROEJA Técnico possui carga horária total mínima de 2400 horas, das quais 1200 horas, no mínimo, são destinadas à formação geral, devendo-se respeitar a carga horária mínima exigida pela 
respectiva habilitação profissional técnica. É destinado a estudantes da EJA que estejam cursando o Ensino Médio.

O Decreto 5.840, de 13 de julho 2006, definiu no parágrafo quinto de seu Art. $1^{\circ}$, as instituições que passaram a integrar, naquele momento, a rede de instituições federais de educação profissional:

Para os fins deste Decreto, a rede de instituições federais de educação profissional compreende a Universidade Federal Tecnológica do Paraná, os Centros Federais de Educação Tecnológica, as Escolas Técnicas Federais, as Escolas Agrotécnicas Federais, as Escolas Técnicas Vinculadas às Universidades Federais e o Colégio Pedro II, sem prejuízo de outras instituições que venham a ser criadas.

Após definir as instituições integrantes da rede federal de educação profissional, o Decreto determinou que a implantação dos cursos e programas do PROEJA, por parte dessas instituições, fosse realizada até o ano de 2007. No que tange ao quantitativo de vagas, estabelece que essas instituições disponibilizariam ao PROEJA, no ano de 2006, o mínimo de $10 \%$ do total das vagas de ingresso na instituição, tendo como referência a quantidade de matrículas realizadas no ano anterior. Ademais, ficou estabelecida a ampliação da oferta de vagas a partir do ano de 2007. O Decreto previu ainda que a ampliação da oferta de vagas fosse incluída no plano de desenvolvimento institucional das instituições federais de ensino.

Mediante o exposto, no texto do Decreto, tem-se a impressão de ser um programa que objetivava assumir grandes proporções, mas que, frente à sua materialização, parece não ter alcançado o sucesso almejado, portanto, depreende-se que seria necessário um grande empenho no sentido de garantir aos jovens e adultos - em sua maioria trabalhadores - o acesso, a permanência e o sucesso na vida escolar.

Muitos são os questionamentos envolvendo as políticas de formação profissional em curso no país, especialmente no que se refere à proposta de qualificação profissional ofertada em período de tempo reduzido - mais especificamente com relação à oferta dos cursos FIC - uma formação aligeirada que não contempla a formação emancipadora e que não garante ao jovem ou adulto trabalhador, no plano prático, $o$ acesso ao capital cultural ideal. Tal fato leva ao questionamento do fator qualidade e, ao mesmo tempo, reforça a ideia da oferta de educação pautada no rompimento entre pensar e agir.

Ramos; Stampa (2016) alertam para o fato de que a democratização do acesso aos programas de educação profissional veio acompanhada da precarização dos processos formativos. Argumentam que:

Do conjunto de iniciativas pragmáticas que se destacam como instrumentos para a criação de uma cultura política de enfrentamento da questão social, as dirigidas à formação dos trabalhadores têm recebido grande atenção, materializando diversas políticas públicas que dialogam com áreas como educação, trabalho e distribuição de renda. É a partir da relação entre essas áreas que desde os anos 1990 vêm sendo ampliadas as vagas em cursos de qualificação profissional no Brasil. Contudo, o que tem sido ampliada é uma proposta formativa para o trabalho simples, sem socialização do conhecimento científico, tecnológico, filosófico e cultural para a maior parcela da classe trabalhadora (RAMOS; STAMPA, 2016, p.102).

No plano do discurso, o MEC apresenta a perspectiva do PROEJA:

[...] o PROEJA tem como perspectiva a proposta de integração da educação profissional à educação básica buscando a superação da dualidade trabalho manual e intelectual, assumindo o trabalho na sua perspectiva criadora e não alienante. Isto impõe a construção de respostas para diversos desafios, tais como, o da formação do profissional, da organização curricular integrada, da utilização de metodologias e mecanismos de 
Considerando a materialização do programa, pode-se afirmar que a perspectiva apresentada se concretizou ou, ao menos, está a caminho de sua concretização. Então, que respostas têm sido apresentadas frente aos desafios elencados?

No que se refere à evasão nos cursos e programas do PROEJA, Hora (2014, p. 132) afirma que "Após sete anos de sua implantação, já se pode afirmar que a média de evasão do programa repete a marca histórica de oferta para Educação de Jovens e Adultos (EJA) no Brasil.” Tal afirmação evidencia a ausência histórica de políticas que favoreçam a permanência na escola.

Reforçando o problema da evasão que assola os cursos e programas do PROEJA, pode-se citar o caso do Instituto Federal de Educação, Ciência e Tecnologia do Sul de Minas Gerais - Campus Passos. O IFSULDEMINAS - Campus Passos ofertou seu primeiro curso do PROEJA, na modalidade PROEJA Técnico, no ano de 2015. A turma iniciou com um total de 26 estudantes dos quais apenas 03 concluíram o curso, segundo informações do Sistema Nacional de Informações da Educação Profissional e Tecnológica - SISTEC. Considerando que houve uma transferência externa e duas desistências formais, o índice de evasão chegou a $77 \%$.

Hora (2014) acrescenta, ainda, que o PROEJA perdeu espaço a partir da criação do Programa Nacional de Acesso ao Ensino Técnico e Emprego - PRONATEC ${ }^{3}$. Como o volume dos investimentos destinados ao PRONATEC era muito grande, as instituições acabaram dispensando maior atenção ao referido programa, fato que acabou por secundarizar o PROEJA, tornando-o "menos sedutor". Uma observação interessante, que vai ao encontro dessa reflexão, pode ser detectada no site do MEC, que disponibiliza documentos e descreve as ações do PROEJA em cada ano. Encontram-se ações dos anos de 2006, 2007, 2008, 2009, 2010 e 2011. Curiosamente, ou não, só existem ações até o ano de 2011, que foi justamente o ano de criação do PRONATEC.

Desse modo, as intenções que permeiam a base legal do PROEJA parecem diluir-se mediante sua materialização. Destaca-se a evasão como um dos grandes desafios a serem enfrentados. Nesse sentido, se faz necessária ações que busquem evidenciar os limites e possibilidades do PROEJA no atendimento a uma expressiva parcela da população que, durante muito tempo, tiveram seus direitos renegados e ainda se encontram em preocupante vulnerabilidade e risco social.

\section{CONSIDERAÇÕES FINAIS}

Apresentou-se, neste artigo de maneira breve o Programa Nacional de Integração da Educação Profissional com a Educação Básica na Modalidade de Educação de Jovens e Adultos - PROEJA, que tem como público-alvo jovens e adultos, partindo de uma reflexão acerca das representações de trabalho e educação no modo de produção capitalista, vinculando o trabalho pedagógico ao serviço do capital, uma vez que busca formar um homem, que se adeque às demandas dos processos produtivos e sociais vigentes.

Destaca-se a tese da empregabilidade, que responsabiliza o indivíduo por sua exclusão do mercado de trabalho numa tentativa de mascarar o desemprego estrutural que assola o atual processo de acumulação flexível. Toda a população, de modo geral, mas especialmente os jovens, têm suas vidas

\footnotetext{
${ }^{3}$ O PRONATEC foi instituído pelo Governo Federal no ano de 2011, através da Lei no 12.513/2011. De acordo com o MEC (n.p.), o programa foi criado "com o objetivo de expandir, interiorizar e democratizar a oferta de cursos de educação profissional e tecnológica no país." Ainda segundo o MEC (n.p.), "O Pronatec busca ampliar as oportunidades educacionais e de formação profissional qualificada aos jovens, trabalhadores e beneficiários de programas de transferência de renda".
} 
diretamente afetadas por esses discursos, na medida em que são vislumbrados enquanto rico potencial de mão de obra. Assim, os jovens tornam-se o principal alvo das políticas de educação profissional.

No Brasil, grande parcela da população ingressa na juventude com defasagem educacional e distorção idade/série, resultante dos fracassos em suas trajetórias escolares, fruto de sucessivas reprovações e evasão escolar, o que compromete o ingresso ao ensino médio e ao ingresso no mercado de trabalho; dessa forma, o PROEJA apresenta-se como uma oportunidade de elevação da escolaridade,

formação profissional e, consequentemente, maiores possibilidades de inserção profissional e social.

Nesse contexto, reconhecemos que esse programa não se configura apenas como instrumento de prevenção a vulnerabilidade entre jovens e adultos das classes populares, mas pode se consolidar como esforço para incorporá-los ao mundo do trabalho valorizando seu potencial transformador da sociedade.

A análise das ações do PROEJA voltadas à população jovem e adulta que não tiveram acesso a educação na idade certa, integra a política educacional do MEC; podemos afirmar, ainda, que a essa categoria social foi conferida certa prioridade no âmbito das políticas educacionais e de formação profissional.

E, para finalizar, sem a pretensão de esgotar as discussões acerca da temática, é importante lembrar que, embora o trabalho e a educação assumam significados que atendam às demandas do capital, no interior do sistema capitalista existem espaços de contradição, e são nesses espaços que seus limites podem ser superados.

\section{REFERÊNCIAS}

ABAD, M. Crítica das políticas de juventude. In: Políticas Públicas: juventude em pauta. Orgs: FREITAS, M.V.de; PAPA, F.de C. São Paulo: Cortez, 2008.

BRASIL. Constituição da República Federativa do Brasil de 1988. Brasília, 05 de out. de 1988. Disponível em < http://www.planalto.gov.br/ccivil 03/Constituicao/Constituicao.htm>. Acesso em: 27 jul. 2016.

BRASIL. Lei $\mathrm{n}^{\circ}$ 9.394, de 20 de dezembro de 1996. Estabelece as diretrizes e bases da educação nacional. Publicada no DOU de 23 dez. 1996. Disponível em: < http://www.planalto.gov.br/ccivil_03/Leis/L9394.htm >. Acesso em: 26 jul. 2016.

BRASIL. Decreto $n^{\circ} 5.478$, de 24 de junho de 2005. Institui, no âmbito das instituições federais de educação tecnológica, o Programa de Integração da Educação Profissional ao Ensino Médio na Modalidade de Educação de Jovens e Adultos - PROEJA. Publicado no DOU de 27 de jun. 2005. Disponível em: < http://www.planalto.gov.br/ccivil_03/_Ato2004-2006/2005/Decreto/D5478.htm> Acesso em: 04 ago. 2016.

BRASIL. Decreto $n^{\circ} 5.840$, de 13 de julho de 2006. Institui, no âmbito federal, o Programa Nacional de Integração da Educação Profissional com a Educação Básica na Modalidade de Educação de Jovens e Adultos - PROEJA, e dá outras providências. Publicado no DOU de 14 de jul. 2006. Disponível em: < http://www.planalto.gov.br/ccivil_03/_Ato2004-2006/2006/Decreto/D5840.htm> Acesso em: 04 ago. 2016.

BRASIL. Lei $\mathrm{n}^{\mathrm{o}} 12.852$, de 5 de agosto de 2013. Institui o Estatuto da Juventude e dispõe sobre os direitos dos jovens, os princípios e diretrizes das políticas públicas de juventude e o Sistema Nacional de Juventude - SINAJUVE. Publicado no DOU de 06 ago. 2013. Disponível em: < http://www.planalto.gov.br/CCIVIL_03/_Ato2011-2014/2013/Lei/L12852.htm >. Acesso em: 26 jul. 2016. 
BRASIL. Ministério Da Educação. Programa Nacional de Acesso ao Ensino Técnico e Emprego -

PRONATEC. Disponível em: < http://portal.mec.gov.br/pronatec >. Acesso em: 14 ago. 2016.

BRASIL. Ministério Da Educação. Programa Nacional de Integração da Educação Profissional com a Educação Básica na Modalidade de Educação de Jovens e Adultos -

PROEJA. 2011. Disponível em: < http://portal.mec.gov.br/proeja >. Acesso em: 14 ago. 2016.

GALVÃO, R.C.S. Educação, cidadania e trabalho. Disponível em: <

http://www.histedbr.fe.unicamp.br/revista/edicoes/25/art14_25.pdf >. Acesso em: 05 ago. 2016.

GENTILI, P. Três teses sobre a relação trabalho e educação em tempos neoliberais. In:

LOMBARDI, J. C.; SAVIANI, D.; SANFELICE, J. L. (Orgs.). Capitalismo, trabalho e educação. 3. ed. Campinas, SP: Autores Associados, Histedbr, 2005. p. 45-59. (Coleção educação contemporânea).

HORA, L.C.A.da. A formação de jovens e adultos trabalhadores sob controle dos empresários: o caso do PROEJA no Maranhão. Disponível em: <

http://periodicos.ifsc.edu.br/index.php/EJA/article/view/1683/pdf\#.V7J1n_krLIU>. Acesso em: 05 ago. 2016.

KUENZER, A.Z. Exclusão includente e inclusão excludente: a nova forma de dualidade estrutural que objetiva as novas relações entre educação e trabalho. In: LOMBARDI, J.C.;SAVIANI, D.;SANFELICE, J. L. (Orgs.). Capitalismo, trabalho e educação. 3. ed. Campinas, SP: Autores Associados, Histedbr, 2005. p. 77-95. (Coleção educação contemporânea).

RAMOS, M.S.; STAMPA, I. Educação Profissional: política de enfrentamento ou de conformação do desemprego da juventude no Brasil?. In: GRACIOLI, M.M. (Org.). Juventude, Trabalho e Emprego: políticas públicas, desafios e perspectivas. Curitiba, CRV, 2016. p. 99-117.

RUA, M.das G. As políticas públicas e a juventude dos anos 90. In: RUA, M.das G. Jovens acontecendo na trilha das políticas públicas. 2 v. Brasília: CNPD, p. 731-752.

SÁ, E.R.de. Políticas públicas de educação profissional: uma análise do PRONATEC com alunos egressos da escola SENAI "Márcio Bagueira Leal". 2016. 131p. Dissertação (Mestrado Profissional Políticas Públicas). Universidade Estadual Paulista, Faculdade de Ciências Humanas e Sociais.

SAVIANI, D. Transformações do capitalismo, do mundo do trabalho e da educação. In: LOMBARDI, J. C.; SAVIANI, D.; SANFELICE, J. L. (Orgs.). Capitalismo, trabalho e educação. 3. ed. Campinas, SP: Autores Associados, Histedbr, 2005. p. 13-24. (Coleção educação contemporânea).

SPOSITO, M. P.; CARRANO, P. C. R. Juventude e políticas públicas no Brasil. Disponível em: < http://www.scielo.br/pdf/\%0D/rbedu/n24/n24a03.pdf >. Acesso em: 01 ago. 2016. 
